\title{
Corpus
}

Archivos virtuales de la alteridad americana

Vol 3, No 2 | 2013

Julio / Diciembre 2013

\section{En los márgenes de la institución. Reflexiones sobre las maneras diversas de ser y dejar de ser católico}

\section{Verónica Giménez Béliveau}

\section{OpenEdition}

\section{Journals}

Edición electrónica

URL: http://journals.openedition.org/corpusarchivos/585

DOI: 10.4000/corpusarchivos.585

ISSN: 1853-8037

Editor

Diego Escolar

\section{Referencia electrónica}

Verónica Giménez Béliveau, «En los márgenes de la institución. Reflexiones sobre las maneras diversas de ser y dejar de ser católico », Corpus [En línea], Vol 3, No 2 | 2013, Publicado el 20 diciembre 2013, consultado el 02 mayo 2019. URL : http://journals.openedition.org/corpusarchivos/585; DOI : 10.4000/corpusarchivos.585

Este documento fue generado automáticamente el 2 mayo 2019.

Licencia Creative Commons: Atribución-NoComercial 2.5 Argentina (CC BY-NC 2.5 AR) 


\title{
En los márgenes de la institución. Reflexiones sobre las maneras diversas de ser y dejar de ser católico
}

\author{
Verónica Giménez Béliveau
}

1 La riqueza de la diversidad del catolicismo ha sido trabajada desde distintas perspectivas. Desde los análisis que identifican sectores doctrinales o ideológicos (Campos Machado y Mariz, 2000; Donatello, 2010), hasta aquellos que analizan posiciones en una jerarquía (Mallimaci, 1993; Esquivel, 2004), pasando por quienes estudian sectores específicos del entramado institucional (Ludueña, 2001, 2008; Irrazábal en prensa), se ha destacado la amplia variedad de opciones hacia el interior del catolicismo, mostrando agentes, modelos organizativos, situaciones, políticas y modalidades de acción diversas. Como afirmaran algunos de sus estudiosos en otras latitudes, la Iglesia es un mundo (Poulat, 1986), y por momentos pareciera ser un mundo en crisis permanente, que va hacia su disolución (Hervieu-Léger, 2003). ¿Cómo abordar desde la sociología a la vez la amplitud y la diversidad, la crisis y el estrechamiento, el florecimiento efervescente y el lento deslizamiento hacia la indiferencia, las pretensiones de hegemonía de ciertos sectores y la voluntad de acuerdo de otros?

2 Una de las maneras de pensar el catolicismo, la entrada que he elegido, es esquivar las posiciones centrales o jerárquicas, e intentar comprender qué pasa en los márgenes. Es en esos espacios liminares, tanto en los márgenes de la institucionalidad, pero como veremos no necesariamente del compromiso, como en los márgenes de la pertenencia, pero sin salir del todo de ciertas referencias, donde se juegan las dinámicas a mi juicio más interesantes del catolicismo actual. Una configuración sin duda más cerca de espacios plurales que de estructuras monopólicas.

3 En este artículo me concentraré en dos espacios sociales distintos para pensar el catolicismo. Primero, trabajaré con las sociabilidades y las identificaciones de quienes participan en comunidades católicas. Movimientos eclesiales, grupos de oración, órdenes religiosas proponen lugares de práctica y de compromiso intensos, y a la vez de compleja 
articulación con las estructuras eclesiales más allá de las comunidades. Luego, me moveré hacia lo que parecería ser un polo opuesto, el de quienes fueron socializados en ambientes católicos en su infancia, pero salieron de ellos, y no se consideran ya parte de religión alguna. Desafiliados (Roof, 1993), indiferentes (Esquivel, 2013), sin religión (Davie, 1994) son algunas de las denominaciones con que se designa a este grupo, que ha adquirido una relevancia creciente en las últimas décadas. Este recorrido exige una reflexión metodológica que nos permita pensar cómo estudiar los distintos espacios, que son aquí abordados a partir de herramientas metodológicas distintas. ${ }^{1}$

\section{Desde los márgenes de la institución: las comunidades y la sociabilidad intensa}

4 Lo que llamo aquí comunidades o grupos de sociabilidad intensa están constituidos por fieles que, en un momento de sus vidas, optan por formas de compromiso activas a partir de orientaciones particulares de cada uno de los núcleos. Las comunidades, fundadas por religiosos o laicos al margen de la estructura administrativa de las parroquias, proponen un tipo de compromiso marcado por tonos específicos: los Scouts buscan generar en los jóvenes vivencias de la fe relacionadas con la vida al aire libre y la propuesta de una vida orientada al servicio del otro, los Carismáticos se destacan por la relación personal que los fieles establecen con la divinidad, los miembros de FASTA (Fraternidad de Agrupaciones Santo Tomás de Aquino) por su interés en la educación y en el resguardo de las tradiciones de la Iglesia y de la Patria, los de Comunión y Liberación por su interés en la sociedad y en la política en sentido amplio, los Focolares por su modo de vida centrado en la unidad y por la práctica del ecumenismo y de la búsqueda de alternativas económicoreligiosas a la sociedad capitalista, sólo por mencionar algunos ejemplos de comunidades católicas particularmente activas en las últimas décadas en el Cono Sur.

5 El origen de las comunidades suele darse en los márgenes de la Iglesia, por la intención de diferenciación respecto de la institución con la que fueron fundadas, por la posición de los fundadores, que a menudo no forman parte de las jerarquías (no son obispos), y por los numerosos conflictos que la mayoría de los grupos han tenido que afrontar con los superiores correspondientes (obispos de las diócesis, episcopados nacionales). El movimiento que lleva a crear una comunidad, aún dentro del catolicismo, supone una carga de protesta respecto de la institución que los grupos asumen: afirmar una identidad concreta y diferenciada al interior de la Iglesia, formar parte de un grupo con pretensiones de autonomía y de una gestión relativamente autoconstruida discute con la Iglesia los límites del control institucional que genera, inevitablemente, algún nivel de conflicto. Lo que las jerarquías leen en la fundación de las comunidades, en un primer momento, es la voluntad de diferenciación, y recién en un segundo momento pueden procesar la utilidad concreta de la ampliación de la oferta de opciones de compromiso para la masa de católicos.

6 Las comunidades católicas tienen sus redes de reclutamiento privilegiadas entre los católicos "de carrera" (Giménez Béliveau, 2007), es decir entre aquellos fieles socializados en espacios católicos desde la niñez, para los cuales el catolicismo "está en el aire", forma parte de sus vidas. Es decir, la efervescencia y el renovado compromiso que las comunidades muestran no es un fenómeno que se extienda en amplios espacios sociales, sino que toma sus recursos de grupos sociales ya atravesados por las sociabilidades 
católicas de diverso tipo. La entrada a la comunidad concreta es, sin embargo, materia de opción personal, y cada fiel la elige siguiendo sus preferencias individuales, su trayectoria de formación, y sobre todo, los caminos que habilita la pertenencia a grupos sociales concretos.

7 Cuando los católicos entran en contacto con el grupo, en general a partir de relaciones personales con otros miembros, la comunidad propone un recorrido de integración que apunta no ya a la socialización en el catolicismo, que los nuevos miembros no necesitan porque ya forman parte de él, y conocen sus rituales, gestualidades, gestión de los tiempos y del espacio, sino a la transmisión de los saberes comunitarios, es decir, cómo se es católico en el grupo específico en el que el fiel ha decidido comprometerse.

Para ello, la comunidad pone en práctica una serie de estructuras diferenciadas que componen un recorrido a la vez de formación y de integración comunitaria. Cada grupo arma el recorrido según distintos criterios y categorías: la Renovación Carismática Católica organiza "Seminarios de Vida" y escuelas de "Discipulado" que se centran en el aprendizaje de la perspectiva carismática de contacto con la divinidad. Así, cuándo recibir la iluminación divina, cómo reconocerla, de qué maneras expresarla y cómo transmitirla constituyen el núcleo básico de los aprendizajes. La Fraternidad de Agrupaciones Santo Tomás de Aquino organiza a sus fieles según una estricta separación según sexo y edad. Así, se escanden grupos de niños (denominados Escuderos), niñas (Caperucitas, Herederas) y adolescentes (Adalides para las mujeres, Templarios para los varones), de jóvenes (los milicianos) y luego de familias (los convivios) (Giménez Béliveau, 2011). Las comunidades también proponen cursus específicos para sus especialistas religiosos, sacerdotes y religiosas, que se forman separados de los laicos, reproduciendo así una división del trabajo que estructura la vivencia de la religión en la Iglesia católica.

La gran diversidad de los criterios que subyacen a las estructuras de encuadramiento de los fieles de las distintas comunidades responden al amplio abanico doctrinal e ideológico de los grupos. Sin embargo, podríamos tratar de pensar las formas básicas de organización a partir de dos polos, cuya tensión en las estructuras organizativas eclesiales no es nueva: la división según "criterios demográficos" de sexo y edad, y la ubicación según "núcleos de acción", siguiendo los intereses o los ámbitos de trabajo de los fieles católicos. Estos polos, que vimos a la obra en las concepciones diferenciadas de la Acción Católica, y en la evolución de la Acción Católica Argentina (Mallimaci, 1991), aún conforman de alguna manera los grandes modelos organizativos de los movimientos eclesiales y las comunidades católicas.

Las comunidades proponen, en suma, un espacio de compromiso intenso, apoyado en la creación de una identidad diferenciada de la Iglesia pero sin salir de ella, y centrada en los parámetros que el grupo destaca, para un sector del catolicismo muy minoritario, dispuesto a asumir un compromiso activo y duradero con una manera de ser católico. Y a la vez que exhiben una gran pluralidad de criterios organizativos y de posiciones políticas respecto de temas de actualidad, componen un mapa de caminos de consolidación del compromiso para católicos en busca de mayores dosis de religión en sus vidas. Los grupos generan militantes, que además están dispuestos a mostrar su identidad a la sociedad a través de signos en el cuerpo, manifestaciones en el espacio público, intervenciones en la prensa. Pensar sociológicamente este tipo de compromiso nos lleva al agrupamiento que Weber (1984) denominaba "de virtuosos", es decir, de aquellos que están dispuestos a extender su religiosidad a todos los aspectos de su vida. 


\section{Desde los márgenes de la pertenencia: los indiferentes y su relación con el catolicismo del que ¿salieron?}

11 El análisis de las comunidades ofrece a quien investiga un camino en el que el método y la teoría se encuentran, y que resulta en cierto modo fácil: entramos al campo desde la comunidad, buscando lazo social, encontramos grupo y relaciones sociales; nos topamos con estructuras de agentes más y menos comprometidos, pero que se definen en relación con la figura del militante, siendo éste el horizonte a alcanzar. Pero para comprender las dinámicas del catolicismo actual hay que pensar también en espacios sociales que no se definen por la pertenencia sino por el alejamiento de ésta, e intentar reflexionar sobre las maneras plurales de relación con las instituciones y las identidades que las personas proponen. Estos espacios, en los que el compromiso se diluye y las pertenencias se disuelven, sin que las creencias se ausenten totalmente, son difíciles de abordar, y exigen buscar maneras de entrada al campo diversas: de hecho, para conocer la relación de los desafiliados con la religión no se puede entrar "por la puerta de la institución" o de la comunidad, ya que estamos frente a un público alejado de las instituciones. Para ello, elegí trabajar con historias de vida, que si bien no me permiten trazar un panorama general, sí habilitan la comprensión de diversas maneras de vivir el proceso de desafiliación.

12 Siguiendo esta línea de abordaje, el espacio social de los católicos desafiliados, me parece un lugar interesante para pensar qué dinámicas atraviesan el catolicismo actual, más allá de las declaraciones de principios de su dirigencia. De hecho, el número de personas de origen católico que se piensa fuera del catolicismo no ha cesado de crecer paulatinamente, desde las dos últimas décadas del siglo XX. Prandi (1996) afirma que "la religión es ahora materia de preferencia, de suerte que aún escoger no tener religión alguna es completamente aceptable socialmente". Parker (1993) aclara, además, que más que de ateos, estamos hablando de "creyentes sin religión", y "creyentes a su manera". Es que los "indiferentes religiosos", que llegan al 11,3\% en Argentina (Mallimaci, Esquivel, Giménez Béliveau, 2013), no carecen de creencias, se trata más bien de un fenómeno ligado a la fuerte desregulación del espacio religioso.

Uno de los primeros elementos que llaman la atención cuando se trabaja con las historias de vida de los católicos desafiliados es la tensión permanente entre lo que se abandonó y lo que permanece. Hay símbolos, rituales, discursos católicos que no sólo son rechazados por quienes se alejan de la religión sino que realmente no tienen ya sentido para ellos. Y en dirección inversa, vemos aparecer marcas y esquemas de pensamiento relacionados con el catolicismo en otros espacios de la vida, aunque vaciados de sus contenidos rituales o doctrinales.

14 Muchos de los católicos desafiliados con los que he trabajado recibieron, durante su infancia, una formación ligada de distintas maneras a las instituciones católicas: bautismo, como la enorme mayoría de los habitantes de Argentina, comunión.

¿De qué maneras encontramos la distancia con la religión transmitida por la familia en los católicos desafiliados? Podemos leerla en un abanico que va desde la negación total de la fe, hasta la afirmación de la creencia pero la desconfianza hacia la institución. Así, Juan, ${ }^{2}$ residente en La Matanza, en la provincia de Buenos Aires, 48 años, transita un camino del 
alejamiento respecto de las creencias religiosas: no asiste a ceremonias religiosas siguiendo necesidades espirituales personales, no lleva medallas ni cruces que invoquen protección, no recurre a la religión en momentos de dolor, ni en momentos de felicidad (Giménez Béliveau, 2012). Por su parte Noelia, ${ }^{3} 24$ años, residente en Buenos Aires, sostiene que "yo no creo en la figura de la iglesia como institución. Si creo en que hay un Dios", y Lucía, 25 años, porteña, sostiene que en un momento de su vida "dejé de creer..., no creo en dios, para mí es un cuento chino".

Pero a la vez que aparece esta distancia, una serie de permanencias de esquemas, matrices, modos de pensar marcados por el catolicismo siguen siendo puestos en práctica por los católicos desafiliados. Es posible identificar variadas formas de permanencia. Una de ellas es la continuidad de ritualidades que tuvieron en un momento un formato religioso, pero sin la presencia eclesiástica y vaciadas de contenido católico. En la familia de Juan, por ejemplo, se siguen celebrando los acontecimientos de la vida (nacimientos, muertes, uniones), pero ya sin el recurso al rito religioso. Para Noelia, el matrimonio es un lugar de proyección importante en su vida personal, y en su proyecto de vida se lee tanto la distancia con la institución como la permanencia del marco ritual: "Yo pienso casarme ante mi Dios. No ante la iglesia, la iglesia es un lugar físico nomás".

Otra forma en la que aparece la permanencia de un repertorio católico es en los modos de pensar el compromiso hacia distintos tipos de tareas sociales. Militancia, trabajo social son ejercidos por algunos de los católicos desafiliados bajo la marca de la religión, aunque sin el contenido de creencias ni el marco ritual de las comunidades o de la institución católica. Por ejemplo, Juan relata el inicio de su militancia en los barrios de La Matanza como un deslizamiento desde un universo católico, en el que en un momento dado deja de encontrar los valores cristianos, hacia el espacio de lo político, donde él siente que aquellos supuestos predicados por el cristianismo se concretan en actividades específicas.

Podemos ver también la permanencia de lugares marcados por el catolicismo como espacios de encuentro consigo mismo, de búsqueda personal en la que la religión no tiene ya lugar. Mariana, por ejemplo, sostiene que "solamente voy a la iglesia, es uno de los espacios que puedo llegar a sentirme bien, en ciertas circunstancias. Es uno de los tantos lugares que uno encuentra, es uno más. Vuelvo a repetirte, no voy a la iglesia a misa y no creo en la iglesia como institución".

Por otro lado, el catolicismo no aparece como la única reserva religioso-espiritual a la que los católicos desafiliados recurren: elementos católicos y también de otras tradiciones religiosas y espirituales se encuentran en los discursos y las prácticas de las persona. El alejamiento y permanenciase articulan bajo el signo de la autonomía. Esta reivindicación de elegir la conexión con la religión según su propia conveniencia es sentida como un derecho irrenunciable: se recurre a la religión, pero en el formato y en el momento que cada persona determina. Como Mariana afirma, "cada uno tiene su propio derecho y su propia forma de pensar y creer".

\section{Conclusiones: el monopolio como pretensión institucional}

20 Los dos espacios sociales que he trabajado aquí discuten las interpretaciones del monopolio católico, cada una desde una perspectiva distinta: el estudio de las comunidades muestra un tipo de compromiso intenso, que se proyecta en el espacio 
público, pero que discute con la idea de una Iglesia que controla todas las sociabilidades dentro del marco del catolicismo. En efecto las comunidades pretenden y ejercen espacios de autonomía que cuestionan la extensión homogénea de la autoridad institucional, mostrando un tipo de catolicismo activo pero minoritario y poco controlado por las máximas jerarquías institucionales.

El análisis de los desafiliados nos muestra en cambio la vitalidad de las dinámicas en los márgenes de la fe: grupos de población creciente entre los cuales la misma enunciación de la pertenencia aparece problematizada, y que circulan en los márgenes del espacio social católico, entrando y saliendo en movimientos marcados por la autonomía. "Entradas" y "salidas" que son más bien una metáfora poco feliz de circulaciones concretas e interpretaciones simbólicas en una zona gris en la que la presencia de la institución es un reflejo, un espejismo, una niebla.

Fugas, reinterpretaciones, reafirmaciones, heterodoxias, mezclas, y sobre todo, recurso autónomo a los discursos, símbolos y rituales que la institución propone por parte de colectivos e individuos afirman la idea que el monopolio católico debe ser pensado como un horizonte utópico institucional, como intentos de la iglesia de imponer una idea de su extensión, más que como la constatación sociológica de una penetración de la institución católica en la sociedad.

\section{BIBLIOGRAFÍA}

Campos Machado, M. y Mariz, C. (2000) Progressistas e católicas carismáticas: umaanálise de discurso de mulheres de comunidades de base naatualidade brasileira. Praia Vermelha, 3, 8-29.

Davie, G. (1994). Religion in Britain since 1945. Oxford: Blackwell.

Donatello, L. M. (2010). Catolicismo y montoneros. Religión, política y desencanto. Buenos Aires: Manantial.

Esquivel, J. C. (2004). Detrás de los muros. La Iglesia católica en tiempos de Alfonsín y Menem (1983-1999). Buenos Aires: Universidad Nacional de Quilmes.

Esquivel, J. C. (2013). Los indiferentes religiosos. En Mallimaci, F., Atlas de las creencias y las prácticas religiosas en Argentina. Buenos Aires: Biblos.

Hervieu-Léger, D. (2003). Catholicisme, la fin d'un monde. Paris: Bayard.

Irrazábal, G. (en prensa). Los académicos pontificios del mundo en la Asamblea de Roma: debates y estrategias transnacionales. En Giménez Béliveau, V., Religión y movimientos: circulaciones, expansiones, migraciones. Buenos Aires: Eudeba.

Giménez Béliveau, V. (2007).Carreras militantes. Comunidades católicas y formación de los sujetos en Argentina.Ciencias Sociales y Religión, 9, 31-58.

Giménez Béliveau, V. (2011).Comunidad, autoridad e institución en el catolicismo. Lógicas de construcción comunitaria en grupos tradicionalistas católicos en Argentina. Si Somos Americanos: Revista Estudios Transfronterizos, vol. XI N², 113-141. 
Giménez Béliveau, V. (2012). Los márgenes de la religión. Indiferentes y católicos desafiliados desde perspectivas metodológicas cruzadas. En Ameigeiras, A.(Comp.), Cruces, intersecciones, conflictos. Relaciones político religiosas en Latinoamérica(pp. 191-206). Buenos Aires: CLACSO.

Ludueña, G. (2001) Dos experiencias místicas de lo numinoso. Numen, vol. 4, № 1, 87- 118.

Ludueña, G. (2008). Tradition and imagination in the creation of a new monastic model in contemporary Hispanic America. International Journal for the study of the Christian Church, vol. 8, issue 1.

Mallimaci, F. (1991) Movimientos laicales y sociedad en el período de entreguerras. La experiencia de la acción católica en Argentina. Cristianismo y Sociedad, 108, 35- 71.

Mallimaci, F. (1993).La continua crítica a la modernidad: análisis de los vota de los obispos argentinos al Concilio Vaticano II. Sociedad y Religión, vol. 10-11, 62-83.

Mallimaci, F., Esquivel, J. C. y Giménez Béliveau, V. (2013). Introducción. En Mallimaci, F., Atlas de las creencias y las prácticas religiosas en Argentina. Buenos Aires: Biblos.

Parker, C. (1993). Otra lógica en América Latina. Religión popular y modernización capitalista. Santiago de Chile: Fondo de Cultura Económica.

Poulat, É. (1986). L'Église, c'estun monde. L'ecclésiosphère. Paris: Cerf.

Prandi, R. (1996). Heredeiras do Axé. São Paulo: Hucitec.

Roof, W. C. (1993) Toward the Year 2000: Reconstructions of Religious Space.Annals of the American Academy of Political and Social Science, 527, 155-170.

Weber, M. (1984) Economía y Sociedad. México DF: Fondo de Cultura Económica.

\section{NOTAS}

1. Las reflexiones de este artículo se basan en trabajos de campo que realicé en momentos diversos en espacios católicos, durante más de 15 años, en distintas provincias de Argentina, y en la zona fronteriza entre Argentina, Brasil y Paraguay denominada "Triple Frontera". El estudio de las comunidades comenzó en 1997 y se cerró en 2004, y desde 2009 retomé algunas comunidades específicas para profundizar ciertas dinámicas católicas. El campo sobre los católicos desafiliados y los indiferentes fue iniciado en 2009, y sigue hasta hoy.

2. Las citas de los dichos de Juan surgen de una serie de entrevistas realizadas en junio de 2010 en Buenos Aires, en el marco del proyecto "Religión y Estructura Social en Argentina en el siglo XXI", dirigido por Fortunato Mallimaci (CONICET/ ANPCYT).

3. Las entrevistas a Noelia, Lucía, Mariana e Ingrid fueron realizadas entre junio y octubre de 2011 Buenos Aires, por Fernando Manzano, en el marco del proyecto "Religión y Estructura Social en Argentina en el siglo XXI”, dirigido por Fortunato Mallimaci (CONICET/ ANPCYT). 


\section{AUTOR}

\section{VERÓNICA GIMÉNEZ BÉLIVEAU}

CEIL/ CONICET- Universidad de Buenos Aires, Argentina.

Correo electrónico: vgimenez@ceil-conicet.gov.ar 